OPEN ACCESS

Edited by:

Diego Ruano,

Universidad de Sevilla, Spain

Reviewed by:

Javier Vitorica,

Universidad de Sevilla, Spain

Yu Tang,

Central South University, China

*Correspondence:

Xinjie Bao

xinjieabao@163.com

Renzhi Wang

wangrz@126.com

Received: 02 May 2018

Accepted: 19 September 2018

Published: 08 October 2018

Citation:

Shen Z, Bao X and Wang R (2018)

Clinical PET Imaging of Microglial Activation: Implications for Microglial

Therapeutics in Alzheimer's Disease.

Front. Aging Neurosci. 10:314.

doi: 10.3389/fnagi.2018.00314

\section{Clinical PET Imaging of Microglial Activation: Implications for Microglial Therapeutics in Alzheimer's Disease}

\author{
Zhiwei Shen, Xinjie Bao* and Renzhi Wang* \\ Department of Neurosurgery, Peking Union Medical College Hospital, Peking Union Medical College, Chinese Academy of \\ Medical Sciences, Beijing, China
}

In addition to extracellular $\beta$-amyloid plaques and intracellular neurofibrillary tangles, neuroinflammation has been identified as a key pathological characteristic of Alzheimer's disease (AD). Once activated, neuroinflammatory cells called microglia acquire different activation phenotypes. At the early stage of $A D$, activated microglia are mainly dominated by the neuroprotective and anti-inflammatory M2 phenotype. Conversely, in the later stage of $\mathrm{AD}$, the excessive activation of microglia is considered detrimental and pro-inflammatory, turning into the M1 phenotype. Therapeutic strategies targeting the modulation of microglia may regulate their specific phenotype. Fortunately, with the rapid development of in vivo imaging methodologies, visualization of microglial activation has been well-explored. In this review, we summarize the critical role of activated microglia during the pathogenesis of $A D$ and current studies concerning imaging of microglial activation in AD patients. We explore the possibilities for identifying activated microglial phenotypes with imaging techniques and highlight promising therapies that regulate the microglial phenotype in AD mice.

Keywords: microglia, therapy, Alzheimer's disease, imaging, phenotype

\section{INTRODUCTION}

Alzheimer's disease (AD), the most common cause of dementia, was first described by Dr. Alois Alzheimer in 1907 (Vishal et al., 2011). From decades of research, it is thought that AD is caused by neuronal and synaptic loss following deposition of extracellular $\beta$-amyloid $(\mathrm{A} \beta)$ plaques and intracellular neurofibrillary tangles (NFTs) (Li et al., 2016). Paradoxically, none of the therapeutic approaches targeting $A \beta$ or NFTs have yet achieved satisfactory outcomes in $A D$ patients. In recent years, an increasing number of studies have recognized that neuroinflammation, mainly driven by activated microglia, also contributes to AD pathogenesis (Calsolaro and Edison, 2016; Ransohoff, 2016a; Bolos et al., 2017; Mathys et al., 2017; Venegas et al., 2017). Activated microglia, just like macrophages in peripheral tissues, largely exist in two polarized states, namely the M1 phenotype and the M2 phenotype (Wes et al., 2016; Subramaniam and Federoff, 2017; Xu et al., 2017). Although, it has been realized that a simple M1 or M2 phenotype may not capture the whole status of activated microglia (Ransohoff, 2016b; Tang and Le, 2016; Plescher et al., 2018), this classification serves as a crucial guide for microglia-targeted treatment in $\mathrm{AD}$ patients. Commonly, the M1 phenotype is associated with the release of pro-inflammatory cytokines, such as tumor necrosis factor (TNF)- $\alpha$ and interleukin (IL)- $1 \beta$, whereas the M2 phenotype is accompanied by 
the production of anti-inflammatory molecules, such as IL-10 and IL-4 (Jimenez et al., 2008; Malm et al., 2015). In light of the opposite states of microglial activation, microglia-targeted therapies should be aimed at changing the microglial status.

However, status modifications of microglial cells are very complex. Microglial activation is accompanied by many changes, including morphology, secretory profile and proliferative response (Streit et al., 2014), so altering the cell phenotype involves diverse aspects of microglia. In addition, cumulative evidence indicates that the neuroprotective M2 microglia gather at the preclinical stage of $\mathrm{AD}$, whereas the neurotoxic M1 microglia peak at the clinical stage (Jimenez et al., 2008; Sarlus and Heneka, 2017). Total microglia activation inhibition will inevitably impair the beneficial function of M2 microglia, thus this kind of treatment is inappropriate and inadvisable. Immunotherapy that boosts or tempers inflammation should be dependent on the microglial phenotypes during the specific stages of $\mathrm{AD}$ in patients.

Because of the various survival times of microglia and the complex stimuli in the microenvironment of the $\mathrm{AD}$ brain, concurrent existence of both the M1 and M2 phenotypes in vivo is common, and understanding which phenotype is dominant at each phase is necessary to take appropriate therapeutic measures. However, accurate biomarkers of the in vivo microglial phenotype have not been discovered yet, and so it is difficult to identify their exact subtypes. Thanks to the rapid development of imaging technologies, imaging microglial activation in vivo is already possible. Although this kind of technology is unable to discriminate the exact phenotype of activated microglia, we can distinguish the phenotype according to the disease stage. Thus, this technique might be applied to direct the treatment of $\mathrm{AD}$ patients in the hospital. Regardless of whether the result is M1 or M2, an anti-microglia agent targeting the M1 phenotype or a pro-microglia agent targeting the M2 phenotype would be most beneficial for $\mathrm{AD}$ patients. In this review, we summarize the critical role of microglial activation in the pathogenesis of $\mathrm{AD}$, review the published studies on imaging of microglial activation, and highlight a novel therapeutic approach that exerts neuroprotective effects by modulating microglial activation states in $\mathrm{AD}$ patients.

\section{PATHOLOGICAL SIGNIFICANCE OF MICROGLIAL PHENOTYPES IN AD}

Microglia are the resident macrophages in the central nervous system (CNS), accounting for 10-15\% of all cells in the brain (Lawson et al., 1992). Normally, they exist in a quiescent state, constantly monitoring their microenvironment, but can be activated by surrounding stimuli. Amyloid plaques, the pathological hallmark of $\mathrm{AD}$, are able to attract and stimulate microglia in vivo (Jung et al., 2015; Chen et al., 2016; Yin et al., 2017). This activation process is diverse and includes microglial proliferation, increased secretion of inflammatory factors, cell surface receptor expression, and a morphological change from ramified to amoeboid (Malm et al., 2015; Wolf et al., 2017). In response to growing $A \beta$ plaques, activated microglia can acquire different phenotypes that play dual roles during $\mathrm{AD}$ pathogenesis. The early activation of microglia that attempt to clear $A \beta$ is considered as protective and anti-inflammatory (Jimenez et al., 2008; Shen et al., 2017), equivalent to the M2 phenotype. Typically, M2-polarized microglia show enhanced phagocytosis (Mandrekar-Colucci et al., 2012), upregulated expression of Ym1 and arginase 1 (ARG1) (Zhang et al., 2017), and increased secretion of anti-inflammatory cytokines, such as IL-4, IL-10, IL-13, and transforming growth factor- $\beta$ (Butovsky et al., 2005; Zhou et al., 2012). However, with continuous development of AD pathology, microglia with an M2 phenotype may become dysfunctional over time and be replaced by cells with an M1 phenotype, which is detrimental and pro-inflammatory (Bronzuoli et al., 2016; Figure 1). Accordingly, M1-polarized microglia are associated with relatively poor phagocytosis and increased secretion of pro-inflammatory cytokines, such as IL-1, IL-6, IL-12, IL-18, and TNF- $\alpha$ (Malm et al., 2015). In support of this idea, one study has demonstrated that increased cortical and hippocampal neurodegeneration induces a shift of activated microglia from M2 to M1 (Kumar et al., 2016). Moreover, M2 microglia in amyloid precursor protein and presenilin $1(A P P / P S 1)$ mutant mice at 6 months of age could, with ongoing $A \beta$ accumulation, switch to an M1 microglial phenotype at 18 months of age (Jimenez et al., 2008).

The pro-inflammatory factors released by M1 microglia have many detrimental effects, resulting in the exacerbation of $\mathrm{AD}$ progression. For example, IL-1, a promotor of IL-6 production and microglial activation, is upregulated in $\mathrm{AD}$ mice and believed to promote $A \beta$ deposition (Heneka and O'Banion, 2007). Though a study has shown that IL-1 $\beta$ overexpression decreases plaque area and frequency (Shaftel et al., 2007), it should be noted that this study was performed in APP/PS1 mice only 6 months of age, which is regarded as an early stage of $\mathrm{AD}$ progression. IL- 6 has recently been found to be a useful biological marker that significantly correlates with the severity of cognitive impairment (Lai et al., 2017). Moreover, some studies have suggested IL-6 is intimately associated with amyloid precursor protein (APP) metabolism (Kalman et al., 1997; Leblhuber et al., 1998; Cojocaru et al., 2011). TNF- $\alpha$, a dual factor relaying both neuron death and neuroprotection, has been shown to be involved in AD-related neuroinflammation and amyloidogenesis via $\beta$-secretase (Cheng et al., 2014). Further, soluble TNF receptors promote the conversion from mild cognitive impairment (MCI) to dementia in patients with MCI (Buchhave et al., 2010; Diniz et al., 2010) and stimulate A $\beta$ production through activation of transcription factors (Buchhave et al., 2010). In addition, increased levels of pro-inflammatory cytokines including IL-1, IL-6, and TNF inhibit the phagocytosis of $\mathrm{A} \beta$ in the brain of $\mathrm{AD}$ model mice (Stamouli and Politis, 2016).

Conversely, M2 microglia provide neuroprotective effects in many ways. Firstly, the anti-inflammatory cytokines they secrete, such as IL-4, IL-10, and TGF- $\beta$, suppress pro-inflammatory cytokine production and action (Rubio-Perez and MorillasRuiz, 2012). In addition, IL-4 inhibits IFN- $\gamma$ and decreases the expression of TNF- $\alpha$ and nitric oxide (Chao et al., 1993). Other 
a) neuroprotective;

b) anti-inflammatory;

c) neurotrophic factors;

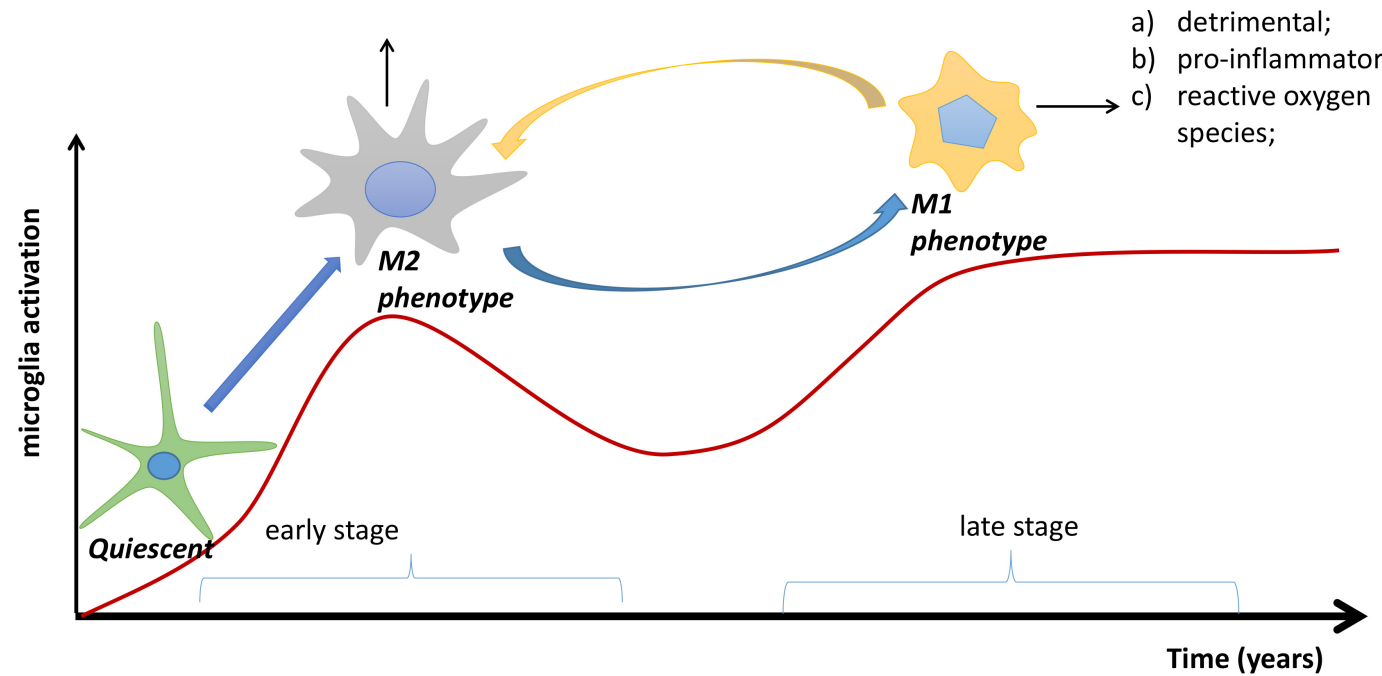

FIGURE 1 | The transformation process of microglial phenotypes in Alzheimer's disease (AD). In the early stage of AD, quiescent microglias are activated to the M2 phenotype by accumulating $A \beta$ plaques; in the later stage, the M2 phenotype may be transformed to the M1 phenotype. Overall, the M2 phenotype is neuroprotective and anti-inflammatory, whereas the M1 phenotype is detrimental and pro-inflammatory. Red line: degree of microglial activation.

studies have shown that IL-10 mediates enhanced neurogenesis (Kiyota et al., 2012) and maintains neuronal homeostasis by inhibiting apoptotic pathways (Strle et al., 2001). In addition, ARG1 and Ym1, the typical biomarkers of M2 microglia, can repair damage to the extracellular matrix (Varnum and Ikezu, 2012; Tang and Le, 2016). Further, the secretion of A $\beta$-degrading enzymes, like insulin-degrading enzyme (Kawahara et al., 2014), is enhanced, along with phagocytic activity (Mandrekar-Colucci et al., 2012). In contrast, a few studies have revealed that antiinflammatory signaling might be detrimental in AD (Town et al., 2008; Chakrabarty et al., 2012, 2015; Guillot-Sestier et al., 2015). The underlying mechanism of this effect has not been explained or demonstrated with solid support by the authors. Thus, further studies about the unwanted side-effects of anti-inflammatory cytokines are still required for AD.

Apart from the M1 and M2 phenotypes, some new microglial activation phenotypes have been recently identified. For example, disease-associated microglia (DAM), a newly identified subset of microglia, have been demonstrated to have a unique transcriptional and functional signature (Keren-Shaul et al., 2017). In the study, the authors characterized the involvement of microglia in a mouse model of $\mathrm{AD}$ by using single-cell sorting, revealing that DAM are activated through a two-step process; that is, from homeostatic microglia to an intermediate state and finally to a fully activated DAM state. The first step is TREM2independent, whereas the second step is TREM2-dependent. DAM are associated with sensory mechanisms, phagocytosis and lipid metabolism, so Keren-Shaul et al. (2017) suggest that the microglia have the potential to restrict $\mathrm{AD}$ progression. However, it remains contentious whether microglia's role is protective or injurious (Brown and St George-Hyslop, 2017). Further study needs to test whether DAM depletion affects disease progression in $\mathrm{AD}$ and whether excessive microglial phagocytosis is deleterious. In addition, using ultrastructural analysis, another study has identified a new microglial phenotype, named dark microglia, that also plays a significant role in the pathological remodeling of neuronal circuits in APP/PS1 mice (Bisht et al., 2016). These phenotypes will need to be better understood for the development of new microglia-targeted treatments.

\section{THE THERAPEUTIC EFFECTS OF DRUGS THAT ACT ON MICROGLIA IN AD}

Despite decades of study, currently there are still no effective therapies available for AD patients, and this mainly arises from incorrect treatment targets. Past studies have focused extensively on reducing $A \beta$ or tau levels. In recent years, research on microglia as potential targets for $\mathrm{AD}$ treatment have gained attention, especially strengthened by a recent discovery in a genome-wide association study (Sims et al., 2017), which found that microglia with variants in PLCG2, ABI3 and TREM2 genes contribute directly to the development of AD. Similarly, a review elucidated that several genes expressed in microglia, including APOE, TREM2, CD33, GRN and IL1RAP, alter AD risk, and therefore could be considered as microglial therapeutic targets (Wes et al., 2016). In addition, microglial functions are largely affected by aging. In the aged brain, microglia are chronically impaired and dysfunctional, transforming into an M1 phenotype, as evidenced by reduced process motility, aberrant morphology, and decreased phagocytic ability (Miller and Streit, 2007; Damani et al., 2011; Daria et al., 2017). However, such microglial 
dysfunction might be reversible (Daria et al., 2017), and the restored microglia may be able to remodel the disease pathology in several ways, including phagocytosis of $A \beta$ plaques, secretion of $A \beta$-degrading enzymes and neurotrophic factors, inhibition of the release of pro-inflammatory factors, and promotion of endogenous neurogenesis (Serini and Calviello, 2016; Shen et al., 2017). Moreover, M2 microglia have the ability to promote remyelination in the CNS (Miron et al., 2013).

Therefore, therapies should reflect the disease stage of a patient and be more specific, such as enhancing the M2 phenotype in the early stage by suppressing activation of M1 or boosting the switch from M1 to M2. Firstly, as stated above, microglia predominantly adopt the M2 phenotype in the early stage, which is beneficial and anti-inflammatory. Thus, early interventions aimed at suppressing overall microglial activation are destructive and should be avoided. Rather, treatment options that increase M2 microglia could promote a neuroprotective effect and contribute to the survival of neurons. For example, a study by Jin et al. (2017) has reported that peritoneal dialysis can enhance the $\mathrm{A} \beta$ phagocytosis function of microglia in $A P P / P S 1$ mice and reduce amyloid-beta plasma levels in humans. Secondly, M1 cells are typically detrimental. They can produce a lot of pro-inflammatory factors like nitric oxide, IL-1, IL-6, and TNF (Koning et al., 2009). M1 cells predominate in the later stage of $\mathrm{AD}$ and greatly aggravate disease progression. Therefore, treatments that interfere with the activation of M1 may be effective in halting lesion development. An increasing number of studies have shown that regulating the ratio of M1/M2 or switching the detrimental M1 phenotype toward the beneficial M2 phenotype can produce a good clinical outcome (Biagioli et al., 2017; Chen et al., 2017; Yao et al., 2017). We recommend that such treatment should be started as early as possible and would be best during the time right when M2 microglias are transitioning to M1 microglia. To sum up, these therapeutic approaches focus on not only decreasing the harmful effects but also enhancing the beneficial effects of neuroinflammation by modulating the ratio of M1/M2. Such microglia-targeted therapies are potential avenues for $\mathrm{AD}$ treatment.

\section{CURRENT IMAGING OF MICROGLIA IN VIVO IN AD PATIENTS}

Undoubtedly, activation of microglia plays a significant role in the underlying pathology of AD. Because of dynamic and context-dependent properties, microglial phenotypes are hard to identify. Understanding which phenotype dominates in vivo at specific times will definitely help in the selection and implementation of efficacious therapeutics. Imaging microglial activation in vivo is a new research field that is providing a better understanding of their function over time. Many imaging techniques have been studied for microglial visualization, such as confocal microscopy, multiphoton microscopic imaging, magnetic resonance imaging (MRI), and Positron emission tomography (PET) (Venneti et al., 2009). The detailed analyses of each technique have been well-reviewed by Venneti et al. (2009). In the following paragraphs, we mainly aim to review the possibility of imaging microglial activation in $\mathrm{AD}$ patients using MRI and PET, which have the potential for further in vivo application in human beings.

High-field MRI scanners, particularly 7 T MRI, have been increasingly used as powerful tools for $\mathrm{AD}$ studies in vivo. The main neuroimaging biomarkers of $7 \mathrm{~T}$ MRI that have been identified for AD patients are neuroanatomical atrophy, molecular characterization of hypo-intensities and micro-infarcts (Ali et al., 2015). Recent studies have shown colocalization of ferritin with microglia in AD patient samples (van Duijn et al., 2013; Kwiatek-Majkusiak et al., 2015), and high-field MRI is quite sensitive to microscopic iron. Thus, it might be possible to detect microglial activation by ultra-high resolution MRI. For instance, a study by Zeineh et al. (2015) has demonstrated that there are numerous small MR hypo-intensities within the hippocampus in late-stage $\mathrm{AD}$ specimens but not in controls, indicating small hypo-intensities are imaging features of activated ironcontaining microglia. Interestingly, another study that assessed metabolite levels using magnetic resonance spectroscopy found that macromolecule and lipid levels (ML9) might represent a biomarker related to the microglial phenotype in mice (Pardon et al., 2016), which thus might help distinguish microglial activation in $\mathrm{AD}$ mouse models. Both the above-mentioned studies have successfully explored the visualization of microglial activation with high-field MRI in mouse or human brain specimens, laying the foundation for future in vivo application in human beings.

Compared with MRI, imaging of microglial activation using PET is much more practical and has been greatly studied in AD patients. Table 1 provides a list of most of the studies that have been published in the PUBMED database with the key words of "microglia," "phenotype," "PET," and "Alzheimer's disease." The $18 \mathrm{kDa}$ translocator protein (TSPO) is the main target for PET studies, and is mainly expressed by activated microglia (Cosenza-Nashat et al., 2009). Though it has been reported that TSPO is expressed both in brain microglia and blood immune cells (Kanegawa et al., 2016), a study by Narayan et al. (2017) has demonstrated that TSPO is downregulated in blood macrophages. In addition, another study has reported the presence of monocyte-derived macrophage infiltration in a very aged mouse model of AD (Martin et al., 2017). There is evidence that TSPO radioligand binding correlates with the abundance of activated microglia (Chen and Guilarte, 2008; Venneti et al., 2008). To date, many kinds of TSPO PET tracers have been used; [11C]-PK11195 is representative of the first generation of PET tracers and has been most widely used. Nevertheless, [11C]PK11195 has several limitations, including low brain uptake, low bioavailability and high lipophilicity (Ching et al., 2012). In comparison, the second generation of TSPO ligands, such as [11C]-PBR28 (Kreisl et al., 2010), [18F]-DPA-714 (Golla et al., 2015) and [11C]-DPA-713 (Endres et al., 2009), exhibit higher affinity and better kinetic characteristics. However, they are sensitive to a polymorphism of the TSPO gene (Ala147Thr) (Owen et al., 2012). The genotypic status of the patients could be classified into low, high, and mixed affinity binders based on this polymorphism (Lagarde et al., 2018). In Table 1, there are three clinical studies that have used the second generation of 
TABLE 1 | Clinical studies of microglial activation by PET imaging in AD patients.

\begin{tabular}{|c|c|c|c|c|}
\hline Subjects & Age & Tracer(s) & Binding change (PET) & Reference \\
\hline 8AD; 15control; $1 \mathrm{MCl}$ & $\begin{array}{l}\text { AD: } \\
66.1 \pm 5.3 \text { years } \\
\text { MCl: } \\
75 \text { years }\end{array}$ & {$[11 \mathrm{C}](\mathrm{R}) \mathrm{PK} 11195$} & Increase in $\mathrm{MCl}$ and $\mathrm{AD}$ & Cagnin et al., 2001 \\
\hline $22 \mathrm{AD} ; 14 \mathrm{MCl}$ & $\begin{array}{l}\mathrm{MCl}: \\
66.6 \pm 9.6 \text { years } \\
\text { AD: } \\
64.9 \pm 6.4 \text { years }\end{array}$ & $\begin{array}{l}{[11 C](R) P K 11195 \text { and }} \\
{[11 C]-P I B}\end{array}$ & Increase in $\mathrm{MCl}$ and $\mathrm{AD}$ & Okello et al., 2009 \\
\hline 10AD; 6control & $\begin{array}{l}\text { AD: } \\
71.8 \pm 9.9 \text { years } \\
\text { Control: } \\
64.5 \pm 5.5 \text { years }\end{array}$ & $\begin{array}{l}\text { [18F]-DPA-714; No TSPO } \\
\text { genotyping }\end{array}$ & $\begin{array}{l}\text { Not significant between } A D \text { and } \\
\text { control }\end{array}$ & Golla et al., 2015 \\
\hline 26AD; $38 \mathrm{MCl}$ & $\begin{array}{l}\text { MCl: } \\
67.8 \pm 9.1 \text { years } \\
\text { AD: } \\
68.3 \pm 12.1 \text { years }\end{array}$ & $\begin{array}{l}{[18 F]-D P A-714 \text { and }[11 \mathrm{C}]-\mathrm{PIB} ;} \\
\text { With TSPO genotyping }\end{array}$ & Increase in both $\mathrm{MCl}$ and $\mathrm{AD}$ & Hamelin et al., 2016 \\
\hline $7 \mathrm{AD} ; 8 \mathrm{MCl}$ & $\begin{array}{l}\mathrm{MCl}: \\
62.6 \pm 7.5 \text { years } \\
\text { AD: } \\
65.1 \pm 6.3 \text { years }\end{array}$ & {$[11 C]-D E D$} & $\begin{array}{l}\text { Increase in } \mathrm{MCl} \text { and } \mathrm{AD} \text {; most } \\
\text { in } \mathrm{MCl}\end{array}$ & Carter et al., 2012 \\
\hline 10AD; 7MCl; 10control & $\begin{array}{l}\text { MCl: } \\
67.1 \pm 9.9 \text { years } \\
\text { AD: } \\
70.2 \pm 7.4 \text { years }\end{array}$ & {$[11 C]-D A A 1106$} & Increase in $\mathrm{MCl}$ and $\mathrm{AD}$ & Yasuno et al., 2012 \\
\hline 19AD; $10 \mathrm{MCl}$ & $\begin{array}{l}\text { AD: } \\
63.1 \pm 8.8 \text { years } \\
\text { MCl: } \\
72.6 \pm 9.7 \text { years }\end{array}$ & $\begin{array}{l}\text { [11C]-PBR28; with partly TSPO } \\
\text { genotyping }\end{array}$ & $\begin{array}{l}\text { Increase in AD; } \\
\text { early-onset > late-onset; } \\
\text { age-dependent }\end{array}$ & Kreisl et al., 2013 \\
\hline 19AD; 10MCl; 21control & $\begin{array}{l}\text { AD: } \\
69 \pm 8 \text { years } \\
\text { MCl: } \\
72 \pm 6 \text { years }\end{array}$ & {$[11 \mathrm{C}](\mathrm{R}) \mathrm{PK} 11195$} & $\begin{array}{l}\text { Subtle increase in AD; no in } \\
\text { prodromal }\end{array}$ & Schuitemaker et al., 2013 \\
\hline 8AD; 14control & $\begin{array}{l}\text { AD: } \\
66 \pm 4.8 \text { years } \\
\text { Control: } \\
65 \pm 5.5 \text { years }\end{array}$ & {$[11 \mathrm{C}](\mathrm{R}) \mathrm{PK} 11195$} & Increase in AD; age-dependent & Fan et al., 2015 \\
\hline $8 \mathrm{AD} ; 17 \mathrm{MCl}$ & $\begin{array}{l}\text { MCl: } \\
61.9 \pm 6.4 \text { years } \\
\text { AD: } \\
63.0 \pm 6.5 \text { years }\end{array}$ & [11C]-DED & $\begin{array}{l}\text { Increase in } \mathrm{AD} \text { and } \mathrm{MCl} \text {; higher } \\
\text { in } \mathrm{MCl} \text {; decline with age }\end{array}$ & Rodriguez-Vieitez et al., 2016 \\
\hline $8 \mathrm{AD} ; 8 \mathrm{MCl}$ & $\begin{array}{l}\text { MCl: } \\
67.7 \pm 6.6 \text { years }\end{array}$ & $\begin{array}{l}\text { TSPO-[11C] (R)PK11195; } \\
{[11 C]-P I B}\end{array}$ & $\begin{array}{l}\text { Increase in } \mathrm{MCl} \text { and } \mathrm{AD} \text {; } \\
\text { longitudinal reduction in } \mathrm{MCl} \text {; } \\
\text { longitudinal increase in } \mathrm{AD}\end{array}$ & Fan et al., 2017 \\
\hline
\end{tabular}

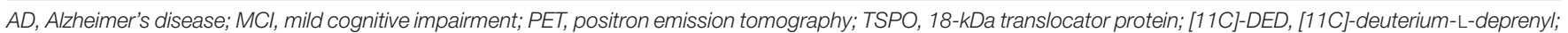

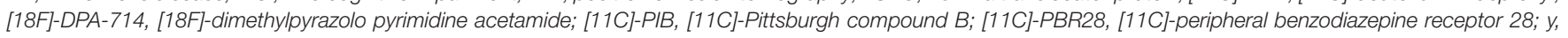
years; $m$, months.

TSPO ligands that require genetic information, including [11C]PBR28 and [18F]-DPA-714. Among them, the studies with TSPO polymorphism genotyping have excluded the individuals with low affinity binders (Kreisl et al., 2013; Hamelin et al., 2016), so their results are more valuable than those that lack TSPO genotype information (Golla et al., 2015).

It should be noted that none of the current TSPO ligands are specific tracers of M1 or M2 microglia. This may be because no clear target of specific subtypes of activated microglia has been discovered to develop PET tracers (Vivash and O'Brien, 2016). Recently, some subtypes of purinergic receptors have been increasingly considered as specific markers of the M1 or M2 status of microglial cells in preclinical research. For example, PET tracers labeled with [11C] were demonstrated to have a highly specific affinity with purinergic receptor subtype 7 (P2X7R, a molecular target for pro-inflammatory microglia) in an animal model (Ory et al., 2016; Territo et al., 2017). Furthermore, a study by Beaino et al. (2017) has demonstrated that P2X7R is associated with a pro-inflammatory phenotype of human microglia, and $\mathrm{P} 2 \mathrm{Y} 12 \mathrm{R}$ is associated with an anti-inflammatory phenotype in postmortem tissues of multiple sclerosis patients, suggesting $\mathrm{P} 2 \mathrm{Y} 12 \mathrm{R}$ and $\mathrm{P} 2 \mathrm{X} 7 \mathrm{R}$ are promising targets for discriminating microglial phenotypes in vivo by PET imaging. Controversially, $\mathrm{P} 2 \mathrm{Y} 12 \mathrm{R}$ is considered a marker of homeostatic microglia that is 
downregulated in neurodegenerative disease status (Keren-Shaul et al., 2017; Zrzavy et al., 2017). Importantly, P2X7R and P2Y12R have been investigated in only animals and postmortem tissues, and their feasibility and practicability in $\mathrm{AD}$ patients are still unknown.

Nonetheless, we have gained many useful insights from the previous clinical studies. Most clinical studies have shown increased TSPO ligand binding in both $\mathrm{AD}$ patients and patients with MCI (Cagnin et al., 2001; Okello et al., 2009; Yasuno et al., 2012; Kreisl et al., 2013; Hamelin et al., 2016), indicating high microglial activation during the two conditions. MCI is defined as a transitional stage between normal function and dementia, which is not severe enough for a diagnosis of $\mathrm{AD}$. Thus, in vivo detection of microglial activation by PET might be quite helpful in the early assessment of neuroinflammation for MCI patients. Moreover, a study by Fan et al. (2017) showed a longitudinal reduction of TSPO binding after the first peak of microglial activation in MCI patients and a longitudinal increase after the second peak of microglial activation in $\mathrm{AD}$ patients. The outcome of this study might be illustrated in Figure 1, which elucidates the discrepancies among the studies in Table 1. These differences, such as the age-dependent increase of TSPO ligand binding in one study (Fan et al., 2015), and its decline with age in another (Rodriguez-Vieitez et al., 2016), might stem from examination at different time points. The transition from M2 to M1 microglia in the progression of $\mathrm{AD}$ has also been identified in PET clinical studies; for example, the microglial activation detected by PET seems to play a protective role at the preclinical stage in $\mathrm{AD}$ patients (Hamelin et al., 2016; Fan et al., 2017). Combined with neurological examinations, including Mini-Mental State Examination scores, detecting microglial activation in vivo could indirectly indicate the current phenotype status based on the specific stage, as the M2 phenotype peaks in the MCI stage and the M1 phenotype dominates in the symptomatic AD stage. In short, by imaging microglial activation, it may be possible to indirectly identify the phenotype of activated microglia to help implement more specific and effective therapeutic approaches.

\section{MICROGLIA-TARGETED THERAPIES IN AD MODEL MICE}

Recently, an increasing number of anti-AD therapies targeting microglia have been discovered in AD animal models. Here, we categorize these new drugs or therapies into three types based on their effects on microglia: M2 enhancement, M1 suppression, and M1/M2 switching. For example, a recent study has shown that deferoxamine treatment induces M2 activation of microglia and significantly ameliorates $\mathrm{A} \beta$ deposition in the hippocampus of 12-month-old APP/PS1 mice (Zhang and He, 2017). In this study, deferoxamine was also found to inhibit M1 activation of microglia and apoptosis in the brain. Thus, it is conceivable that enhancement of the M2 phenotype may be beneficial for AD treatment in the early stage.

Anti-inflammatory strategies have been proposed because the neuroinflammatory response is considered as a key factor in the pathogenesis of $\mathrm{AD}$. However, it needs to be noted that anti-inflammatory strategies should mainly be targeted at the detrimental M1 phenotype rather than the neuroprotective M2 phenotype. For example, minocycline has recently been shown to inhibit the pro-inflammatory phenotype of microglia and enhance phagocytosis of $\mathrm{A} \beta$ deposits (El-Shimy et al., 2015). Besides M1 suppression and M2 enhancement, shifting the M1 phenotype to the M2 phenotype has been the most proposed as a potential therapeutic direction for $\mathrm{AD}$ treatment. An increasing number of drugs have been identified that modulate the transition of M1 to M2 in AD model mice, including Lipoxin A4 (Medeiros et al., 2013), IL-33 (Fu et al., 2016), GW2580 (Olmos-Alonso et al., 2016), EGb761 (Wan et al., 2016), and Iso- $\alpha$-acids (Ano et al., 2017). This kind of regulation could generate multiple beneficial effects. They reduce the level of pro-inflammatory cytokines and increase the level of anti-inflammatory factors; additionally, microglia of the M2 phenotype have been demonstrated to have improved phagocytic function and reduce $A \beta$ deposits. All of these effects correlate with an improved performance in cognition and memory, implying that shifting the microglial M1 phenotype to an M2 phenotype is a promising approach for treatment of AD patients.

Beyond the above drug explorations, in recent years, stem cell transplantation has been shown to effectively prevent memory impairment and improve cognitive function in $\mathrm{AD}$ model mice (Lee et al., 2010, 2016; Kanamaru et al., 2015). The mechanisms involved in stem cell therapies are diverse and mainly include neuronal replacement (Abdel-Salam, 2011), neurotrophic support (Marsh and Blurton-Jones, 2017), and immunomodulation (Shen et al., 2017). Immunomodulation, particularly the effect on microglia, plays a key role during stem cell transplantation for AD (Shen et al., 2017). For example, adipose-derived mesenchymal stem cell therapy can induce activated microglia into an alternatively activated phenotype in AD model mice (Ma et al., 2013). Another study has found that neural stem cell treatment in APP/PS1 mice significantly improves cognitive deficits via suppression of microglial activation (Zhang et al., 2016). In addition, bone marrow-derived mesenchymal stem cells promote microglial activation and reduce the level of $\mathrm{A} \beta$ deposits in the brain of an acutely induced AD model (Lee et al., 2009). These results demonstrate that stem cell therapies cannot only enhance M2 microglia but also suppress M1 microglia and shift the M1 phenotype to M2, indicating that stem cell transplantation may have a beneficial effect regardless of the treatment time point. However, when to implement this kind of therapy for the most beneficial effect is still an open question that requires further study.

Microglia-targeted therapies in AD also include geneticallydefined therapeutic targets (Wes et al., 2016), treatments to restore the homeostatic microglial phenotype (Ofengeim et al., 2017) and treatments that increase $A \beta$ uptake by microglia (Frenkel et al., 2013; Maezawa et al., 2018; Rangaraju et al., 2018). These approaches, though not purported to be associated with M2 enhancement, M1 suppression or the switch from M1 to M2 microglia, have attempted to modify microglial function from the disease state toward a more anti-inflammatory tone. 


\section{CONCLUSION}

In summary, microglial activation plays a significant role in the underlying pathology of AD. Typically, activated microglia adopt a protective M2 phenotype at the early stage and a detrimental M1 phenotype at the later stage of $\mathrm{AD}$ progression. Current imaging methodologies, such as MRI and PET, are able to detect microglial activation in vivo. Although there are currently no specific biomarkers for M1 or M2 microglia in clinical studies, increasing evidence suggests PET may be a useful tool to assess the extent of microglial activation in AD patients. Thus, together with behavioral function scoring, imaging of microglial activation may help clinicians indirectly identify the current microglial phenotype. After clarification of the phenotype of activated microglia, a directed therapy targeting that specific microglial phenotype should then be implemented, such as M1 suppression, M2 enhancement or M1/M2 switching. Further work is needed to develop feasible innovative PET tracers that can accurately recognize the specific phenotype of activated microglia in $\mathrm{AD}$ patients. Some subtypes of purinergic receptors, such as P2X7R and $\mathrm{P} 2 \mathrm{Y} 12 \mathrm{R}$, have been validated as promising PET imaging

\section{REFERENCES}

Abdel-Salam, O. M. (2011). Stem cell therapy for Alzheimer's disease. CNS Neurol. Disord. Drug Targets 10, 459-485. doi: 10.2174/18715271179556 3976

Ali, R., Goubran, M., Choudhri, O., and Zeineh, M. M. (2015). Seven-Tesla MRI and neuroimaging biomarkers for Alzheimer's disease. Neurosurg. Focus 39:E4. doi: 10.3171/2015.9.FOCUS15326

Ano, Y., Dohata, A., Taniguchi, Y., Hoshi, A., Uchida, K., Takashima, A., et al. (2017). Iso-alpha-acids, bitter components of beer, prevent inflammation and cognitive decline induced in a mouse model of Alzheimer's disease. J. Biol. Chem. 292, 3720-3728. doi: 10.1074/jbc.M116.763813

Beaino, W., Janssen, B., Kooij, G., van der Pol, S. M. A., van Het Hof, B., van Horssen, J., et al. (2017). Purinergic receptors P2Y12R and P2X7R: potential targets for PET imaging of microglia phenotypes in multiple sclerosis. J. Neuroinflamm. 14:259. doi: 10.1186/s12974-017-1034-z

Biagioli, M., Carino, A., Cipriani, S., Francisci, D., Marchiano, S., Scarpelli, P., et al. (2017). The bile acid receptor GPBAR1 regulates the M1/M2 phenotype of intestinal macrophages and activation of GPBAR1 rescues mice from murine colitis. J. Immunol. 199, 718-733. doi: 10.4049/jimmunol.1700183

Bisht, K., Sharma, K. P., Lecours, C., Sanchez, M. G., El Hajj, H., Milior, G., et al. (2016). Dark microglia: a new phenotype predominantly associated with pathological states. Glia 64, 826-839. doi: 10.1002/glia.22966

Bolos, M., Perea, J. R., and Avila, J. (2017). Alzheimer's disease as an inflammatory disease. Biomol. Concepts 8, 37-43. doi: 10.1515/bmc-2016-0029

Bronzuoli, M. R., Iacomino, A., Steardo, L., and Scuderi, C. (2016). Targeting neuroinflammation in Alzheimer's disease. J. Inflamm. Res. 9, 199-208. doi: $10.2147 /$ JIR.S86958

Brown, G. C., and St George-Hyslop, P. H. (2017). Deciphering microglial diversity in Alzheimer's disease. Science 356, 1123-1124. doi: 10.1126/science.aan7893

Buchhave, P., Zetterberg, H., Blennow, K., Minthon, L., Janciauskiene, S., and Hansson, O. (2010). Soluble TNF receptors are associated with Abeta metabolism and conversion to dementia in subjects with mild cognitive impairment. Neurobiol. Aging 31, 1877-1884. doi: 10.1016/j.neurobiolaging. 2008.10.012

Butovsky, O., Talpalar, A. E., Ben-Yaakov, K., and Schwartz, M. (2005). Activation of microglia by aggregated beta-amyloid or lipopolysaccharide impairs MHCII expression and renders them cytotoxic whereas IFN-gamma and IL-4 render them protective. Mol. Cell. Neurosci. 29, 381-393. doi: 10.1016/j.mcn.2005. 03.005 targets for microglia phenotypes in preclinical studies. These studies will be extremely important for microglia-targeted AD therapies, given that microglial phenotypes vary according to disease stage.

\section{AUTHOR CONTRIBUTIONS}

RW and XB co-designed the manuscript. ZS wrote and edited the content. XB revised the draft. All authors read and approved the final manuscript.

\section{FUNDING}

This work was supported by National High Technology Research and Development Program of China (2013AA020106 and 2014AA020513), National Basic Research Program of China (2014CB541603), National Natural Science Foundation of China (81671272), Beijing Natural Science Foundation (7182134), CAMS Initiative for Innovative Medicine (CAMS-I2M and 2016I2M-1-017), and Beijing Nova Program (Z181100006218003).

Cagnin, A., Brooks, D. J., Kennedy, A. M., Gunn, R. N., Myers, R., Turkheimer, F. E., et al. (2001). In-vivo measurement of activated microglia in dementia. Lancet 358, 461-467. doi: 10.1016/S0140-6736(01)05625-2

Calsolaro, V., and Edison, P. (2016). Neuroinflammation in Alzheimer's disease: current evidence and future directions. Alzheimers Dement. 12, 719-732. doi: 10.1016/j.jalz.2016.02.010

Carter, S. F., Scholl, M., Almkvist, O., Wall, A., Engler, H., Langstrom, B., et al. (2012). Evidence for astrocytosis in prodromal Alzheimer disease provided by $11 \mathrm{C}$-deuterium-L-deprenyl: a multitracer PET paradigm combining $11 \mathrm{C}$ Pittsburgh compound B and 18F-FDG. J. Nucl. Med. 53, 37-46. doi: 10.2967/ jnumed.110.087031

Chakrabarty, P., Li, A., Ceballos-Diaz, C., Eddy, J. A., Funk, C. C., Moore, B., et al. (2015). IL-10 alters immunoproteostasis in APP mice, increasing plaque burden and worsening cognitive behavior. Neuron 85, 519-533. doi: 10.1016/j.neuron. 2014.11.020

Chakrabarty, P., Tianbai, L., Herring, A., Ceballos-Diaz, C., Das, P., and Golde, T. E. (2012). Hippocampal expression of murine IL-4 results in exacerbation of amyloid deposition. Mol. Neurodegener. 7:36. doi: 10.1186/1750-1326-7-36

Chao, C. C., Molitor, T. W., and Hu, S. (1993). Neuroprotective role of IL-4 against activated microglia. J. Immunol. 151, 1473-1481.

Chen, J., Sun, Z., Jin, M., Tu, Y., Wang, S., Yang, X., et al. (2017). Inhibition of AGEs/RAGE/Rho/ROCK pathway suppresses non-specific neuroinflammation by regulating BV2 microglial M1/M2 polarization through the NF-kappaB pathway. J. Neuroimmunol. 305, 108-114. doi: 10.1016/j.jneuroim.2017. 02.010

Chen, M. K., and Guilarte, T. R. (2008). Translocator protein 18 kDa (TSPO): molecular sensor of brain injury and repair. Pharmacol. Ther. 118, 1-17. doi: 10.1016/j.pharmthera.2007.12.004

Chen, W., Abud, E. A., Yeung, S. T., Lakatos, A., Nassi, T., Wang, J., et al. (2016). Increased tauopathy drives microglia-mediated clearance of beta-amyloid. Acta Neuropathol. Commun. 4:63. doi: 10.1186/s40478-016-0336-1

Cheng, X., Shen, Y., and Li, R. (2014). Targeting TNF: a therapeutic strategy for Alzheimer's disease. Drug Discov. Today 19, 1822-1827. doi: 10.1016/j.drudis. 2014.06.029

Ching, A. S., Kuhnast, B., Damont, A., Roeda, D., Tavitian, B., and Dolle, F. (2012). Current paradigm of the $18-\mathrm{kDa}$ translocator protein (TSPO) as a molecular target for PET imaging in neuroinflammation and neurodegenerative diseases. Insights Imaging. 3, 111-119. doi: 10.1007/s13244-011-0128-x

Cojocaru, I. M., Cojocaru, M., Miu, G., and Sapira, V. (2011). Study of interleukin-6 production in Alzheimer's disease. Roman. J. Int. Med. 49, 55-58. 
Cosenza-Nashat, M., Zhao, M. L., Suh, H. S., Morgan, J., Natividad, R., Morgello, S., et al. (2009). Expression of the translocator protein of $18 \mathrm{kDa}$ by microglia, macrophages and astrocytes based on immunohistochemical localization in abnormal human brain. Neuropathol. Appl. Neurobiol. 35, 306-328. doi: 10. 1111/j.1365-2990.2008.01006.x

Damani, M. R., Zhao, L., Fontainhas, A. M., Amaral, J., Fariss, R. N., and Wong, W. T. (2011). Age-related alterations in the dynamic behavior of microglia. Aging Cell 10, 263-276. doi: 10.1111/j.1474-9726.2010.00660.x

Daria, A., Colombo, A., Llovera, G., Hampel, H., Willem, M., Liesz, A., et al. (2017). Young microglia restore amyloid plaque clearance of aged microglia. EMBO J. 36, 583-603. doi: 10.15252/embj.201694591

Diniz, B. S., Teixeira, A. L., Ojopi, E. B., Talib, L. L., Mendonca, V. A., Gattaz, W. F., et al. (2010). Higher serum sTNFR1 level predicts conversion from mild cognitive impairment to Alzheimer's disease. J. Alzheimers Dis. 22, 1305-1311. doi: 10.3233/JAD-2010-100921

El-Shimy, I. A., Heikal, O. A., and Hamdi, N. (2015). Minocycline attenuates Abeta oligomers-induced pro-inflammatory phenotype in primary microglia while enhancing Abeta fibrils phagocytosis. Neurosci. Lett. 609, 36-41. doi: 10.1016/j.neulet.2015.10.024

Endres, C. J., Pomper, M. G., James, M., Uzuner, O., Hammoud, D. A., Watkins, C. C., et al. (2009). Initial evaluation of 11C-DPA-713, a novel TSPO PET ligand, in humans. J. Nucl. Med. 50, 1276-1282. doi: 10.2967/jnumed.109.062265

Fan, Z., Brooks, D. J., Okello, A., and Edison, P. (2017). An early and late peak in microglial activation in Alzheimer's disease trajectory. Brain 140, 792-803. doi: 10.1093/brain/aww349

Fan, Z., Okello, A. A., Brooks, D. J., and Edison, P. (2015). Longitudinal influence of microglial activation and amyloid on neuronal function in Alzheimer's disease. Brain 138, 3685-3698. doi: 10.1093/brain/awv288

Frenkel, D., Wilkinson, K., Zhao, L., Hickman, S. E., Means, T. K., Puckett, L., et al. (2013). Scaral deficiency impairs clearance of soluble amyloid-beta by mononuclear phagocytes and accelerates Alzheimer's-like disease progression. Nat. Commun. 4:2030. doi: 10.1038/ncomms3030

Fu, A. K., Hung, K. W., Yuen, M. Y., Zhou, X., Mak, D. S., Chan, I. C., et al. (2016). IL-33 ameliorates Alzheimer's disease-like pathology and cognitive decline. Proc. Natl. Acad. Sci. U.S.A. 113, E2705-E2713. doi: 10.1073/pnas.1604032113

Golla, S. S., Boellaard, R., Oikonen, V., Hoffmann, A., van Berckel, B. N., Windhorst, A. D., et al. (2015). Quantification of [18F]DPA-714 binding in the human brain: initial studies in healthy controls and Alzheimer's disease patients. J. Cereb. Blood Flow Metab. 35, 766-772. doi: 10.1038/jcbfm.2014.261

Guillot-Sestier, M. V., Doty, K. R., Gate, D., Rodriguez, J. Jr., Leung, B. P., et al. (2015). Il10 deficiency rebalances innate immunity to mitigate Alzheimer-like pathology. Neuron 85, 534-548. doi: 10.1016/j.neuron.2014.12.068

Hamelin, L., Lagarde, J., Dorothee, G., Leroy, C., Labit, M., Comley, R. A., et al. (2016). Early and protective microglial activation in Alzheimer's disease: a prospective study using 18F-DPA-714 PET imaging. Brain 139, 1252-1264. doi: 10.1093/brain/aww017

Heneka, M. T., and O’Banion, M. K. (2007). Inflammatory processes in Alzheimer's disease. J. Neuroimmunol. 184, 69-91. doi: 10.1016/j.jneuroim.2006. 11.017

Jimenez, S., Baglietto-Vargas, D., Caballero, C., Moreno-Gonzalez, I., Torres, M., Sanchez-Varo, R., et al. (2008). Inflammatory response in the hippocampus of PS1M146L/APP751SL mouse model of Alzheimer's disease: age-dependent switch in the microglial phenotype from alternative to classic. J. Neurosci. 28, 11650-11661. doi: 10.1523/JNEUROSCI.3024-08.2008

Jin, W. S., Shen, L. L., Bu, X. L., Zhang, W. W., Chen, S. H., Huang, Z. L., et al. (2017). Peritoneal dialysis reduces amyloid-beta plasma levels in humans and attenuates Alzheimer-associated phenotypes in an APP/PS1 mouse model. Acta Neuropathol. 134, 207-220. doi: 10.1007/s00401-017-1721-y

Jung, C. K., Keppler, K., Steinbach, S., Blazquez-Llorca, L., and Herms, J. (2015). Fibrillar amyloid plaque formation precedes microglial activation. PLoS One 10:e0119768. doi: 10.1371/journal.pone.0119768 doi: 10.1371/journal.pone. 0119768

Kalman, J., Juhasz, A., Laird, G., Dickens, P., Jardanhazy, T., Rimanoczy, A., et al. (1997). Serum interleukin-6 levels correlate with the severity of dementia in Down syndrome and in Alzheimer's disease. Acta Neurol. Scand. 96, 236-240. doi: 10.1111/j.1600-0404.1997.tb00275.x

Kanamaru, T., Kamimura, N., Yokota, T., Nishimaki, K., Iuchi, K., Lee, H., et al. (2015). Intravenous transplantation of bone marrow-derived mononuclear cells prevents memory impairment in transgenic mouse models of Alzheimer's disease. Brain Res. 1605, 49-58. doi: 10.1016/j.brainres.2015.02.011

Kanegawa, N., Collste, K., Forsberg, A., Schain, M., Arakawa, R., Jucaite, A., et al. (2016). In vivo evidence of a functional association between immune cells in blood and brain in healthy human subjects. Brain Behav. Immun. 54, 149-157. doi: 10.1016/j.bbi.2016.01.019

Kawahara, K., Suenobu, M., Ohtsuka, H., Kuniyasu, A., Sugimoto, Y., Nakagomi, M., et al. (2014). Cooperative therapeutic action of retinoic acid receptor and retinoid $\mathrm{x}$ receptor agonists in a mouse model of Alzheimer's disease. J. Alzheimers Dis. 42, 587-605. doi: 10.3233/JAD-132720

Keren-Shaul, H., Spinrad, A., Weiner, A., Matcovitch-Natan, O., DvirSzternfeld, R., Ulland, T. K., et al. (2017). A unique microglia type associated with restricting development of Alzheimer's disease. Cell 169:e17. doi: 10.1016/j.cell.2017.05.018

Kiyota, T., Ingraham, K. L., Swan, R. J., Jacobsen, M. T., Andrews, S. J., and Ikezu, T. (2012). AAV serotype 2/1-mediated gene delivery of antiinflammatory interleukin-10 enhances neurogenesis and cognitive function in APP + PS1 mice. Gene Ther. 19, 724-733. doi: 10.1038/gt.2011.126

Koning, N., Uitdehaag, B. M., Huitinga, I., and Hoek, R. M. (2009). Restoring immune suppression in the multiple sclerosis brain. Prog Neurobiol. 89, 359-368. doi: 10.1016/j.pneurobio.2009.09.005

Kreisl, W. C., Fujita, M., Fujimura, Y., Kimura, N., Jenko, K. J., Kannan, P., et al. (2010). Comparison of [(11)C]-(R)-PK 11195 and [(11)C]PBR28, two radioligands for translocator protein $(18 \mathrm{kDa})$ in human and monkey: implications for positron emission tomographic imaging of this inflammation biomarker. Neuroimage 49, 2924-2932. doi: 10.1016/j.neuroimage.2009. 11.056

Kreisl, W. C., Lyoo, C. H., McGwier, M., Snow, J., Jenko, K. J., Kimura, N., et al. (2013). In vivo radioligand binding to translocator protein correlates with severity of Alzheimer's disease. Brain 136, 2228-2238. doi: 10.1093/brain/ awt145

Kumar, A., Alvarez-Croda, D. M., Stoica, B. A., Faden, A. I., and Loane, D. J. (2016). Microglial/macrophage polarization dynamics following traumatic brain injury. J. Neurotrauma 33, 1732-1750. doi: 10.1089/neu.2015.4268

Kwiatek-Majkusiak, J., Dickson, D. W., Tacik, P., Aoki, N., Tomasiuk, R., Koziorowski, D., et al. (2015). Relationships between typical histopathological hallmarks and the ferritin in the hippocampus from patients with Alzheimer's disease. Acta Neurobiol. Exp. (Wars). 75, 391-398.

Lagarde, J., Sarazin, M., Bottlaender, M. (2018). In vivo PET imaging of neuroinflammation in Alzheimer's disease. J. Neural Transm. (Vienna) 125, 847-867. doi: 10.1007/s00702-017-1731-x

Lai, K. S. P., Liu, C. S., Rau, A., Lanctot, K. L., Kohler, C. A., Pakosh, M., et al. (2017). Peripheral inflammatory markers in Alzheimer's disease: a systematic review and meta-analysis of 175 studies. J. Neurol. Neurosurg. Psychiatry 88, 876-882. doi: 10.1136/jnnp-2017-316201

Lawson, L. J., Perry, V. H., and Gordon, S. (1992). Turnover of resident microglia in the normal adult mouse brain. Neuroscience 48, 405-415. doi: 10.1016/03064522(92)90500-2

Leblhuber, F., Walli, J., Tilz, G. P., Wachter, H., and Fuchs, D. (1998). [Systemic changes of the immune system in patients with Alzheimer's dementia]. Dtsch. Med. Wochenschr. 123, 787-791. doi: 10.1055/s-2007-1024069

Lee, J. H., Oh, I. H., and Lim, H. K. (2016). Stem cell therapy: a prospective treatment for Alzheimer's disease. Psychiatry Investig. 13, 583-589. doi: 10.4306/ pi.2016.13.6.583

Lee, J. K., Jin, H. K., and Bae, J. S. (2009). Bone marrow-derived mesenchymal stem cells reduce brain amyloid-beta deposition and accelerate the activation of microglia in an acutely induced Alzheimer's disease mouse model. Neurosci. Lett. 450, 136-141. doi: 10.1016/j.neulet.2008.11.059

Lee, J. K., Jin, H. K., and Bae, J. S. (2010). Bone marrow-derived mesenchymal stem cells attenuate amyloid beta-induced memory impairment and apoptosis by inhibiting neuronal cell death. Curr. Alzheimer Res. 7, 540-548. doi: 10.2174/ 156720510792231739

Li, X., Bao, X., and Wang, R. (2016). Experimental models of Alzheimer's disease for deciphering the pathogenesis and therapeutic screening (Review). Int. J. Mol. Med. 37, 271-283. doi: 10.3892/ijmm.2015.2428

Ma, T., Gong, K., Ao, Q., Yan, Y., Song, B., Huang, H., et al. (2013). Intracerebral transplantation of adipose-derived mesenchymal stem cells alternatively activates microglia and ameliorates neuropathological deficits in 
Alzheimer's disease mice. Cell Transplant. 22(Suppl. 1), S113-S126. doi: 10. 3727/096368913X672181

Maezawa, I., Nguyen, H. M., Di Lucente, J., Jenkins, D. P., Singh, V., Hilt, S., et al. (2018). Kv1.3 inhibition as a potential microglia-targeted therapy for Alzheimer's disease: preclinical proof of concept. Brain 141, 596-612. doi: 10. 1093/brain/awx346

Malm, T. M., Jay, T. R., and Landreth, G. E. (2015). The evolving biology of microglia in Alzheimer's disease. Neurotherapeutics 12, 81-93. doi: 10.1007/ s13311-014-0316-8

Mandrekar-Colucci, S., Karlo, J. C., and Landreth, G. E. (2012). Mechanisms underlying the rapid peroxisome proliferator-activated receptor-gammamediated amyloid clearance and reversal of cognitive deficits in a murine model of Alzheimer's disease. J. Neurosci. 32, 10117-10128. doi: 10.1523/JNEUROSCI. 5268-11.2012

Marsh, S. E., and Blurton-Jones, M. (2017). Neural stem cell therapy for neurodegenerative disorders: the role of neurotrophic support. Neurochem. Int. 106, 94-100. doi: 10.1016/j.neuint.2017.02.006

Martin, E., Boucher, C., Fontaine, B., and Delarasse, C. (2017). Distinct inflammatory phenotypes of microglia and monocyte-derived macrophages in Alzheimer's disease models: effects of aging and amyloid pathology. Aging Cell 16, 27-38. doi: 10.1111/acel.12522

Mathys, H., Adaikkan, C., Gao, F., Young, J. Z., Manet, E., Hemberg, M., et al. (2017). Temporal tracking of microglia activation in neurodegeneration at single-cell resolution. Cell Rep. 21, 366-380. doi: 10.1016/j.celrep.2017.09.039

Medeiros, R., Kitazawa, M., Passos, G. F., Baglietto-Vargas, D., Cheng, D., Cribbs, D. H., et al. (2013). Aspirin-triggered lipoxin A4 stimulates alternative activation of microglia and reduces Alzheimer disease-like pathology in mice. Am. J. Pathol. 182, 1780-1789. doi: 10.1016/j.ajpath.2013.01.051

Miller, K. R., and Streit, W. J. (2007). The effects of aging, injury and disease on microglial function: a case for cellular senescence. Neuron Glia Biol. 3, 245-253. doi: 10.1017/S1740925X08000136

Miron, V. E., Boyd, A., Zhao, J. W., Yuen, T. J., Ruckh, J. M., Shadrach, J. L., et al. (2013). M2 microglia and macrophages drive oligodendrocyte differentiation during CNS remyelination. Nat. Neurosci. 16, 1211-1218. doi: 10.1038/nn.3469

Narayan, N., Mandhair, H., Smyth, E., Dakin, S. G., Kiriakidis, S., Wells, L., et al. (2017). The macrophage marker translocator protein (TSPO) is down-regulated on pro-inflammatory 'M1' human macrophages. PLoS One 12:e0185767. doi: 10.1371/journal.pone.0185767 doi: 10.1371/journal.pone.0185767

Ofengeim, D., Mazzitelli, S., Ito, Y., DeWitt, J. P., Mifflin, L., Zou, C., et al. (2017). RIPK1 mediates a disease-associated microglial response in Alzheimer's disease. Proc. Natl. Acad. Sci. U.S.A. 114, E8788-E8797. doi: 10.1073/pnas.1714175114

Okello, A., Edison, P., Archer, H. A., Turkheimer, F. E., Kennedy, J., Bullock, R., et al. (2009). Microglial activation and amyloid deposition in mild cognitive impairment: a PET study. Neurology 72, 56-62. doi: 10.1212/01.wnl. $0000338622.27876 .0 \mathrm{~d}$

Olmos-Alonso, A., Schetters, S. T., Sri, S., Askew, K., Mancuso, R., VargasCaballero, M., et al. (2016). Pharmacological targeting of CSF1R inhibits microglial proliferation and prevents the progression of Alzheimer's-like pathology. Brain 139, 891-907. doi: 10.1093/brain/awv379

Ory, D., Celen, S., Gijsbers, R., Van Den Haute, C., Postnov, A., Koole, M., et al. (2016). Preclinical evaluation of a P2X7 receptor-selective radiotracer: PET studies in a rat model with local overexpression of the human P2X7 receptor and in nonhuman primates. J. Nucl. Med. 57, 1436-1441. doi: 10.2967/jnumed. 115.169995

Owen, D. R., Yeo, A. J., Gunn, R. N., Song, K., Wadsworth, G., Lewis, A., et al. (2012). An 18-kDa translocator protein (TSPO) polymorphism explains differences in binding affinity of the PET radioligand PBR28. J. Cereb. Blood Flow Metab. 32, 1-5. doi: 10.1038/jcbfm.2011.147

Pardon, M. C., Yanez Lopez, M., Yuchun, D., Marjanska, M., Prior, M., Brignell, C., et al. (2016). Magnetic resonance spectroscopy discriminates the response to microglial stimulation of wild type and Alzheimer's disease models. Sci. Rep. 6:19880. doi: $10.1038 /$ srep19880

Plescher, M., Seifert, G., Hansen, J. N., Bedner, P., Steinhauser, C., and Halle, A. (2018). Plaque-dependent morphological and electrophysiological heterogeneity of microglia in an Alzheimer's disease mouse model. Glia 66, 1464-1480. doi: 10.1002/glia.23318

Rangaraju, S., Dammer, E. B., Raza, S. A., Rathakrishnan, P., Xiao, H., Gao, T., et al. (2018). Identification and therapeutic modulation of a pro-inflammatory subset of disease-associated-microglia in Alzheimer's disease. Mol. Neurodegener. 13:24. doi: 10.1186/s13024-018-0254-8

Ransohoff, R. M. (2016a). How neuroinflammation contributes to neurodegeneration. Science 353, 777-783. doi: 10.1126/science.aag2590

Ransohoff, R. M. (2016b). A polarizing question: do M1 and M2 microglia exist? Nat. Neurosci. 19, 987-991. doi: 10.1038/nn.4338

Rodriguez-Vieitez, E., Saint-Aubert, L., Carter, S. F., Almkvist, O., Farid, K., Scholl, M., et al. (2016). Diverging longitudinal changes in astrocytosis and amyloid PET in autosomal dominant Alzheimer's disease. Brain 139, 922-936. doi: 10.1093/brain/awv404

Rubio-Perez, J. M., and Morillas-Ruiz, J. M. (2012). A review: inflammatory process in Alzheimer's disease, role of cytokines. ScientificWorldJournal 2012:756357. doi: $10.1100 / 2012 / 756357$

Sarlus, H., and Heneka, M. T. (2017). Microglia in Alzheimer's disease. J. Clin. Invest. 127, 3240-3249. doi: 10.1172/JCI90606

Schuitemaker, A., Kropholler, M. A., Boellaard, R., van der Flier, W. M., Kloet, R. W., van der Doef, T. F., et al. (2013). Microglial activation in Alzheimer's disease: an (R)-[(1)(1)C]PK11195 positron emission tomography study. Neurobiol. Aging 34, 128-136. doi: 10.1016/j.neurobiolaging.2012. 04.021

Serini, S., and Calviello, G. (2016). Reduction of oxidative/nitrosative stress in brain and its involvement in the neuroprotective effect of n-3 PUFA in Alzheimer's disease. Curr. Alzheimer Res. 13, 123-134. doi: 10.2174/ 1567205012666150921101147

Shaftel, S. S., Kyrkanides, S., Olschowka, J. A., Miller, J. N., Johnson, R. E., and O'Banion, M. K. (2007). Sustained hippocampal IL-1 beta overexpression mediates chronic neuroinflammation and ameliorates Alzheimer plaque pathology. J. Clin. Invest. 117, 1595-1604. doi: 10.1172/JCI31450

Shen, Z., Li, X., Bao, X., and Wang, R. (2017). Microglia-targeted stem cell therapies for Alzheimer disease: a preclinical data review. J. Neurosci. Res. 95, 2420-2429. doi: 10.1002/jnr.24066

Sims, R., van der Lee, S. J., Naj, A. C., Bellenguez, C., Badarinarayan, N., Jakobsdottir, J., et al. (2017). Rare coding variants in PLCG2, ABI3, and TREM2 implicate microglial-mediated innate immunity in Alzheimer's disease. Nat. Genet. 49, 1373-1384. doi: 10.1038/ng.3916

Stamouli, E. C., and Politis, A. M. (2016). [Pro-inflammatory cytokines in Alzheimer's disease]. Psychiatriki 27, 264-275. doi: 10.22365/jpsych.2016. 274.264

Streit, W. J., Xue, Q. S., Tischer, J., and Bechmann, I. (2014). Microglial pathology. Acta Neuropathol. Commun. 2:142.

Strle, K., Zhou, J. H., Shen, W. H., Broussard, S. R., Johnson, R. W., Freund, G. G., et al. (2001). Interleukin-10 in the brain. Crit. Rev. Immunol. 21, 427-449. doi: 10.1615/CritRevImmunol.v21.i5.20

Subramaniam, S. R., and Federoff, H. J. (2017). Targeting microglial activation states as a therapeutic avenue in Parkinson's disease. Front. Aging Neurosci. 9:176. doi: 10.3389/fnagi.2017.00176 doi: 10.3389/fnagi.2017.00176

Tang, Y., and Le, W. (2016). Differential roles of M1 and M2 microglia in neurodegenerative diseases. Mol. Neurobiol. 53, 1181-1194. doi: 10.1007/ s12035-014-9070-5

Territo, P. R., Meyer, J. A., Peters, J. S., Riley, A. A., McCarthy, B. P., Gao, M., et al. (2017). Characterization of (11)C-GSK1482160 for targeting the P2X7 receptor as a biomarker for neuroinflammation. J. Nucl. Med. 58, 458-465.

Town, T., Laouar, Y., Pittenger, C., Mori, T., Szekely, C. A., Tan, J., et al. (2008). Blocking TGF-beta-Smad2/3 innate immune signaling mitigates Alzheimer-like pathology. Nat. Med. 14, 681-687. doi: 10.1038/nm1781

van Duijn, S., Nabuurs, R. J., van Duinen, S. G., and Natte, R. (2013). Comparison of histological techniques to visualize iron in paraffin-embedded brain tissue of patients with Alzheimer's disease. J. Histochem. Cytochem. 61, 785-792. doi: $10.1369 / 0022155413501325$

Varnum, M. M., and Ikezu, T. (2012). The classification of microglial activation phenotypes on neurodegeneration and regeneration in Alzheimer's disease brain. Arch. Immunol. Ther. Exp. (Warsz). 60, 251-266. doi: 10.1007/s00005012-0181-2

Venegas, C., Kumar, S., Franklin, B. S., Dierkes, T., Brinkschulte, R., Tejera, D., et al. (2017). Microglia-derived ASC specks cross-seed amyloid-beta in Alzheimer's disease. Nature 552, 355-361. doi: 10.1038/nature25158

Venneti, S., Wang, G., Nguyen, J., and Wiley, C. A. (2008). The positron emission tomography ligand DAA1106 binds with high affinity to activated microglia 
in human neurological disorders. J. Neuropathol. Exp. Neurol. 67, 1001-1010. doi: 10.1097/NEN.0b013e318188b204

Venneti, S., Wiley, C. A., and Kofler, J. (2009). Imaging microglial activation during neuroinflammation and Alzheimer's disease. J. Neuroimmune Pharmacol. 4, 227-243. doi: 10.1007/s11481-008-9142-2

Vishal, S., Sourabh, A., and Harkirat, S. (2011). Alois Alzheimer (1864-1915) and the Alzheimer syndrome. J. Med. Biogr. 19, 32-33. doi: 10.1258/jmb.2010. 010037

Vivash, L., and O'Brien, T. J. (2016). Imaging microglial activation with TSPO PET: lighting up neurologic diseases? J. Nucl. Med. 57, 165-168. doi: 10.2967/jnumed. 114.141713

Wan, W., Zhang, C., Danielsen, M., Li, Q., Chen, W., Chan, Y., et al. (2016). EGb761 improves cognitive function and regulates inflammatory responses in the APP/PS1 mouse. Exp. Gerontol. 81, 92-100. doi: 10.1016/j.exger.2016. 05.007

Wes, P. D., Sayed, F. A., Bard, F., and Gan, L. (2016). Targeting microglia for the treatment of Alzheimer's disease. Glia. 64, 1710-1732. doi: 10.1002/glia.22988

Wolf, S. A., Boddeke, H. W., and Kettenmann, H. (2017). Microglia in physiology and disease. Annu. Rev. Physiol. 79, 619-643. doi: 10.1146/annurev-physiol022516-034406

Xu, H., Wang, Z., Li, J., Wu, H., Peng, Y., Fan, L., et al. (2017). The polarization states of microglia in TBI: a new paradigm for pharmacological intervention. Neural Plast. 2017:5405104. doi: 10.1155/2017/5405104

Yao, X., Liu, S., Ding, W., Yue, P., Jiang, Q., Zhao, M., et al. (2017). TLR4 signal ablation attenuated neurological deficits by regulating microglial M1/M2 phenotype after traumatic brain injury in mice. J. Neuroimmunol. 310, 38-45. doi: 10.1016/j.jneuroim.2017.06.006

Yasuno, F., Kosaka, J., Ota, M., Higuchi, M., Ito, H., Fujimura, Y., et al. (2012). Increased binding of peripheral benzodiazepine receptor in mild cognitive impairment-dementia converters measured by positron emission tomography with [(1)(1)C]DAA1106. Psychiatry Res. 203, 67-74. doi: 10.1016/j.pscychresns. 2011.08.013

Yin, Z., Raj, D., Saiepour, N., Van Dam, D., Brouwer, N., Holtman, I. R., et al. (2017). Immune hyperreactivity of Abeta plaque-associated microglia in Alzheimer's disease. Neurobiol. Aging 55, 115-122. doi: 10.1016/j. neurobiolaging.2017.03.021
Zeineh, M. M., Chen, Y., Kitzler, H. H., Hammond, R., Vogel, H., and Rutt, B. K. (2015). Activated iron-containing microglia in the human hippocampus identified by magnetic resonance imaging in Alzheimer disease. Neurobiol. Aging 36, 2483-2500. doi: 10.1016/j.neurobiolaging.2015. 05.022

Zhang, P., Li, Y., Han, X., Xing, Q., and Zhao, L. (2017). Dexmedetomidine regulates 6-hydroxydopamine-induced microglial polarization. Neurochem. Res. 42, 1524-1532. doi: 10.1007/s11064-017-2209-9

Zhang, Q., Wu, H. H., Wang, Y., Gu, G. J., Zhang, W., and Xia, R. (2016). Neural stem cell transplantation decreases neuroinflammation in a transgenic mouse model of Alzheimer's disease. J. Neurochem. 136, 815-825. doi: 10.1111/jnc. 13413

Zhang, Y., and He, M. L. (2017). Deferoxamine enhances alternative activation of microglia and inhibits amyloid beta deposits in APP/PS1 mice. Brain Res. 1677, 86-92. doi: 10.1016/j.brainres.2017.09.019

Zhou, X., Spittau, B., and Krieglstein, K. (2012). TGFbeta signalling plays an important role in IL4-induced alternative activation of microglia. J. Neuroinflamm. 9:210. doi: 10.1186/1742-2094-9-210

Zrzavy, T., Hametner, S., Wimmer, I., Butovsky, O., Weiner, H. L., and Lassmann, H. (2017). Loss of 'homeostatic' microglia and patterns of their activation in active multiple sclerosis. Brain 140, 1900-1913. doi: 10.1093/brain/ awx113

Conflict of Interest Statement: The authors declare that the research was conducted in the absence of any commercial or financial relationships that could be construed as a potential conflict of interest.

The reviewer JV and handling Editor declared their shared affiliation at the time of the review.

Copyright $\odot 2018$ Shen, Bao and Wang. This is an open-access article distributed under the terms of the Creative Commons Attribution License (CC BY). The use, distribution or reproduction in other forums is permitted, provided the original author(s) and the copyright owner(s) are credited and that the original publication in this journal is cited, in accordance with accepted academic practice. No use, distribution or reproduction is permitted which does not comply with these terms. 